GRASAS Y ACEITES 67 (3)

July-September 2016, e147

ISSN-L: 0017-3495

doi: http://dx.doi.org/10.3989/gya.1001153

\title{
Recovery of iron after Fenton-like secondary treatment of olive mill wastewater by nano-filtration and low-pressure reverse osmosis membranes
}

\author{
J.M. Ochando-Pulido ${ }^{\bowtie}$, M.D. Víctor-Ortega and A. Martínez-Férez \\ Chemical Engineering Department, University of Granada, 18071 Granada, Spain \\ ${ }^{\square}$ Corresponding author: jmochandop@ugr.es
}

Submitted: 22 September 2015; Accepted: 16 May 2016

\begin{abstract}
SUMMARY: In this work, the performances of novel nano-filtration (NF) and low-pressure reverse osmosis (RO) polymeric membranes were examined with the aim of recovering the iron used as catalyst in former secondary treatment based on the Fenton-like advanced oxidation of olive mill wastewater (OMW). Results highlight that both membranes exhibit a good performance towards the rejection of iron $(99.1 \%$ for the NF membrane $v s .100 \%$ for the low-pressure RO membrane) in the secondary-treated OMW effluent, thus permitting the recovery of iron in the concentrate stream in order to recycle it back into the oxidation reactor to reduce catalyst consumption. Finally, the permeate streams could be re-used for irrigation. Major productivity was observed by the selected NF membrane, about $47.4 \mathrm{~L} / \mathrm{hm}^{2}$ upon 9 bar, whereas $30.9 \mathrm{~L} / \mathrm{hm}^{2}$ could be yielded with the RO membrane under an operating pressure of 8 bar. Moreover, a sensibly lower fouling index was measured on the NF membrane (0.0072 in contrast with 0.065$)$, which ensures major steady-state performance on this membrane and a longer service lifetime. This also results in lower required membrane area and membrane plant over dimension (4 modules in case of RO operation whereas only 2 modules for NF).
\end{abstract}

KEYWORDS: Iron recovery; Nano-filtration; Olive mill wastewater; Reverse osmosis; Wastewater treatment

RESUMEN: Recuperación de hierro tras tratamiento secundario tipo Fenton de agua residual de la industria oleícola por membranas de nanofiltración y ósmosis inversa de baja presión. En este trabajo, se examinó el rendimiento de membranas modernas de nanofiltración (NF) y ósmosis inversa (OI) poliméricas con el objetivo de recuperar el hierro utilizado como catalizador en un tratamiento secundario previo de agua residual oleícola (OMW) basado en oxidación avanzada tipo Fenton. Los resultados ponen de relieven que ambas membranas exhiben buen rendimiento en cuanto al rechazo de hierro ( $99.1 \%$ para la membrana de NF vs. $100 \%$ para la membrana de OI de bajas presiones) en el efluente oleícola tras tratamiento secundario, permitiendo en consecuencia la recuperación de hierro en la corriente de concentrado para su recirculación de nuevo al reactor de oxidación para reducir el consumo de catalizador. Finalmente, las corrientes de permeado podrían ser reutilizadas para riego. Por otro lado, la productividad asegurada por la membrana de NF seleccionada fue mayor, en torno a $47.4 \mathrm{~L} / \mathrm{hm}^{2}$ a 9 bar, mientras que $30.9 \mathrm{~L} / \mathrm{hm}^{2}$ pudieron ser producidos por la membrana de OI bajo una presión operativa de 8 bar. Además, un índice de fouling sensiblemente menor fue medido en la membrana de $\mathrm{NF}(0.0072$ en contraste con 0.065$)$, lo que asegura mayor rendimiento en estado estacionario para esta membrana, y mayor vida de servicio. Además, ello también resultó en una menor área de membrana y sobredimensionamiento de la planta requeridas (4 módulos en caso de OI mientras que sólo para NF).

PALABRAS CLAVE: Agua residual de la industria oleicola; Nanofiltración; Ósmosis inversa; Recuperación de hierro; Tratamiento de aguas residuales

Citation/Cómo citar este artículo: Ochando-Pulido JM, Víctor-Ortega MD, Martínez-Férez A. 2016. Recovery of iron after Fenton-like secondary treatment of olive mill wastewater by nano-filtration and low-pressure reverse osmosis membranes. Grasas Aceites 67 (3): e147. doi: http://dx.doi.org/10.3989/gya.1001153.

Copyright: (C) 2016 CSIC. This is an open-access article distributed under the terms of the Creative Commons Attribution-Non Commercial (by-nc) Spain 3.0 Licence. 


\section{INTRODUCTION}

One of the key tasks of catalytic processes, from the point of view of cost-efficiency, is the recovery and re-use of the catalyst. This is especially relevant in the case of catalytic treatments aimed for the reclamation of wastewater streams, in which the low added-value of the treated effluent (purified water) makes it imperative to save as much expense as possible. In the case of homogeneous catalytic processes, this is even more difficult to achieve. In the case of heterogeneous catalytic processes, one of the most common solutions can be the fixation of the catalyst to a solid phase. However, this can make the catalyst lose some of its effectiveness, given that a less perfect mix may be achieved. Moreover, in case of dark media like wastewater streams, another problem is added to the former, which is the hindrance of the penetration of light, in the case of photo-catalyzed processes.

In a previous work by the Authors (OchandoPulido et al., 2013a and 2014; Stoller et al., 2015), a novel self lab-made $\mathrm{TiO}_{2}$-based ferromagneticcore photo-catalyst was developed in the framework of the European project PHOTOMEM (Contract FP7-SME-2010-1 no. 262470). The ferromagnetic properties of this catalyst enhanced its recovery back from the wastewater stream by magnetic traps, enabling its re-use in successive batches, solving the problem of the recovery of the catalyst and thus enhancing the cost-effectiveness of the process (Ochando-Pulido et al., 2013a and 2014; Stoller et al., 2015).

In this research paper, an alternative is proposed to our previous work, in this case for two-phase olive mill wastewater (OMW) previously subjected to a secondary treatment based on a homogeneous Fenton-like reaction (Hodaifa et al., 2013a, b; Martínez Nieto, 2011a, b). The goal was to experimentally evaluate the feasibility of the recovery of the iron used as catalyst (ferric chloride) by means of membrane technology in the Fenton-like advanced oxidation process conducted to enhance the degradation of the organic matter in OMW. The goal was to re-use the recovered iron, by separating and concentrating it, in order to pump it back into the Fenton-like reactor to reduce catalyst consumption.

Much effort has been invested to attain novel membranes capable of offering higher technical and economical performances since the development and commercialization of the first cellulose acetate asymmetric membranes. The availability of new membrane materials, designs, module configurations and know-how has succeeded in the promotion of credibility among investors (Akdemir and Ozer, 2009; Stoller, 2008, 2009 and 2011; Turano et al., 2002).

In the last decades, the effluents generated by olive oil industries (OMW) have significantly increased as a result of the boost of the olive oil agro-industrial sector, also due to the technological conversion into continuous operation centrifugation-based processes. Currently, average-sized modern olive oil mills operating with the two-phase centrifugation technology by-produce daily between 10 and $15 \mathrm{~m}^{3}$ of wastewater derived from the vertical centrifugation process, called olive oil washing wastewater (OOW), together with $1 \mathrm{~m}^{3}$ of olive washing wastewater (OWW) per ton of processed olives (Hodaifa et al., 2008; Hodaifa et al., 2013a,b; MartínezNieto et al., 2010, 2011a,b; Ochando-Pulido et al., 2012a,b, 2013a,b). This reaches several million cubic meters of OMW each year.

A wide variety of stand-alone and integrated processes for the treatment of OMW have already been proposed and developed but have not yet led to completely satisfactory results (Borja et al., 2006), such as lagooning or natural evaporation and thermal concentration (Annesini and Gironi, 1991; Paraskeva and Diamadopoulos, 2006), composting (Cegarra et al., 1996; Papadimitriou et al., 1997), treatments with clay (Al-Malah et al., 2000) or with lime (Aktas et al., 2001), biological processes (Ena et al., 2007; Garrido et al., 2002; Marques, 2001; Hodaifa et al., 2008), physico-chemical procedures including coagulation-flocculation (Sarika et al., 2005), electro-coagulation (Inan et al., 2004; Tezcan et al., 2006) and biosorption (Hodaifa et al., 2013a), advanced oxidation processes comprising ozonation (Beltrán et al., 2000), Fenton's reaction (MartínezNieto et al., 2011a; Hodaifa et al., 2013b) and photocatalysis (Sacco et al., 2012), electrochemical treatments (Papastefanakis et al., 2010) and hybrid processes (Grafias et al., 2010; Lafi et al., 2009).

The disposal of the solid waste stream is not the objective of the present work, which aims only at the management problem related to the reclamation of liquid effluents. Some solutions already proposed for the management of the pomace waste are for instance adsorption of heavy metals (Baccar et al., 2009), dyes (Akar et al., 2009) and phenols (Stasinakis et al., 2009) as well as composting (Haddadin et al., 2009) or biogas production (Tekin et al., 2000), among others.

Olive oil industries in their current status, typically small, dispersed mills, cannot afford such high treatment costs. In addition, conventional physicochemical treatments are not effective for the removal of the significant salinity of OMW, reflected in high electro-conductivity (EC), which presents hazardous salinity levels according to the guidelines established by the Food and Agricultural Organization (F.A.O.) for irrigation uses.

Several works have been conducted in the past by means of membrane technology with the aim at reducing the organic load of OMW (Akdemir et al., 2009; Coskun et al., 2010; Turano et al., 2002; Stoller, 2009), but only a few focus on two-phase 
(Ochando-Pulido et al., 2012a; Ochando-Pulido et al., 2012b). Furthermore, some authors have tried to extract the added-value compounds contained in this effluent, mainly low-molecular-weight polyphenols and sugars by concentration with membranes (Garcia-Castello et al., 2010; Paraskeva et al., 2007; Russo, 2007).

In this work, two different membranes, one nanofiltration (NF) and a low-pressure reverse osmosis (RO), are examined with a double aim: the main one is the recovery of the iron used as catalyst in the former Fenton-like secondary treatment of OMW, but at the same time a secondary goal was the removal of the high EC and remaining organic matter in this secondary-treated OMW stream.

For this purpose, the adequate operating pressure for both membranes was studied, with an insight into the impacts on both the productivity and rejection efficiency towards the target species. The fouling issues occurring on both membranes, which deeply influence the performance and costeffectiveness of the membrane process, were also analyzed and taken into account for the membrane plant dimension. Control of fouling is a key parameter in order to increase the profitability of membrane processes during operation and avoid excessive overdesign of the membrane plants. High fouling rates on the membranes would rapidly lead to zero flux conditions in an irreversible way in case of iron (Yiantsios and Karabelas, 2002).

Finally, the suitability for reusing the final effluent (permeate stream) in the olive oil production process and therefore closing the loop was also checked.

\section{MATERIALS AND METHODS}

\subsection{Feedstock: two-phase olive mill wastewater}

Samples of OWW and OOW effluents were collected from several two-phase centrifugation-based olive oil mills in the Andalusian provinces of Jaén and Granada (Spain) during winter months and rapidly analyzed in the lab and refrigerated for further research when necessary.

OWW and OOW were mixed in a 1:1 (v/v) proportion to stabilize the average organic matter concentration of the effluent stream (OMW) entering the treatment system and thus avoiding sensible fluctuations in the COD parameter. After this, OMW was conducted to a secondary treatment on a pilot scale based on Fenton-like advanced oxidation process. The secondary treatment is described in detail in former works by the authors (MartínezNieto et al., 2010, 2011a, 2011b; Hodaifa et al., 2013a, 2013b). The OMW effluent after the secondary treatment will be hereafter subjected to the final membrane operation.

\subsection{Membranes plant}

The membrane plant used for the experiments was a bench-scale one supplied by Prozesstechnik $\mathrm{GmbH}$ (Basel, Switzerland), provided with a plateand-frame module (Figure 1). Flat-sheet RO and NF membranes were selected for the experiments, supplied by GE Water and Process Technologies, with the characteristics reported in Table 1.

The membranes plant consists of a non-stirred double walled tank (5 L) and a diaphragm pump (Hydra-Cell model D-03) to drive the effluent stream to a plate-and-frame membrane module M1 (dimensions $3.9 \mathrm{~cm}$ width $\times 33.5 \mathrm{~cm}$ length). The plant is also provided with another different membrane module (M2), which can be either a spiralwound or tubular one, and can be selected with a three-way valve (V6).

The main processing parameters (operating pressure, temperature and feed flow rate) were measured and displayed. The operating pressure could be adjusted finely with a spring-loaded pressureregulating valve (SS-R4512MM-SP, Swagelok) on the concentrate outlet and monitored by a digital pressure gauge (Endress+Hauser, model Ceraphant T PTC31), allowing independent control of the operating pressure $\left(\mathrm{P}_{\mathrm{TM} \text { set point }} \pm 0.01\right.$ bar $)$ and the flow rate; the feed flow rate was regulated by means of a feed flow rate valve $\left(\mathrm{F}_{\text {set point }} \pm 0.1 \mathrm{~L} / \mathrm{h}\right)$ to fix the tangential velocity over the membrane (Mott and Untener, 2014); the operating temperature was regulated automatically $\left(\mathrm{T}_{\text {set point }} \pm 0.1^{\circ} \mathrm{C}\right)$ via a proportional-integral-derivative (PID) electronic temperature controller (Yokogawa model UT100) and a magnetic valve in the cooling loop, which re-circulates cooling water coming from a chiller (PolyScience model 7306) inside the tank's refrigerating jacket. The system is also automatically protected against excess pressure and temperature. All medium wetted metallic parts are made of stainless steel 316L to avoid corrosion, except the permeate and concentrate stream outlet tubes, which are made of chemical resistant polyethylene.

\subsection{NF and RO performances: experimental procedure}

Prior to each NF or RO experiment, the corresponding membrane was stabilized by filtering MilliQ ${ }^{\circledR}$ water at a fixed pressure and temperature until a constant and stable flux was observed. After this, the hydraulic permeabilities $\left(\mathrm{m}_{0}\right)$ of each of the selected membranes were determined by measuring the pure water flux over the admissible applied pressures range of each one, at ambient temperature and turbulent cross-flow velocity.

Subsequently, 2 L of secondary-treated OMW were poured into the feed-water tank to proceed with the experimental OMW membranes purification. 


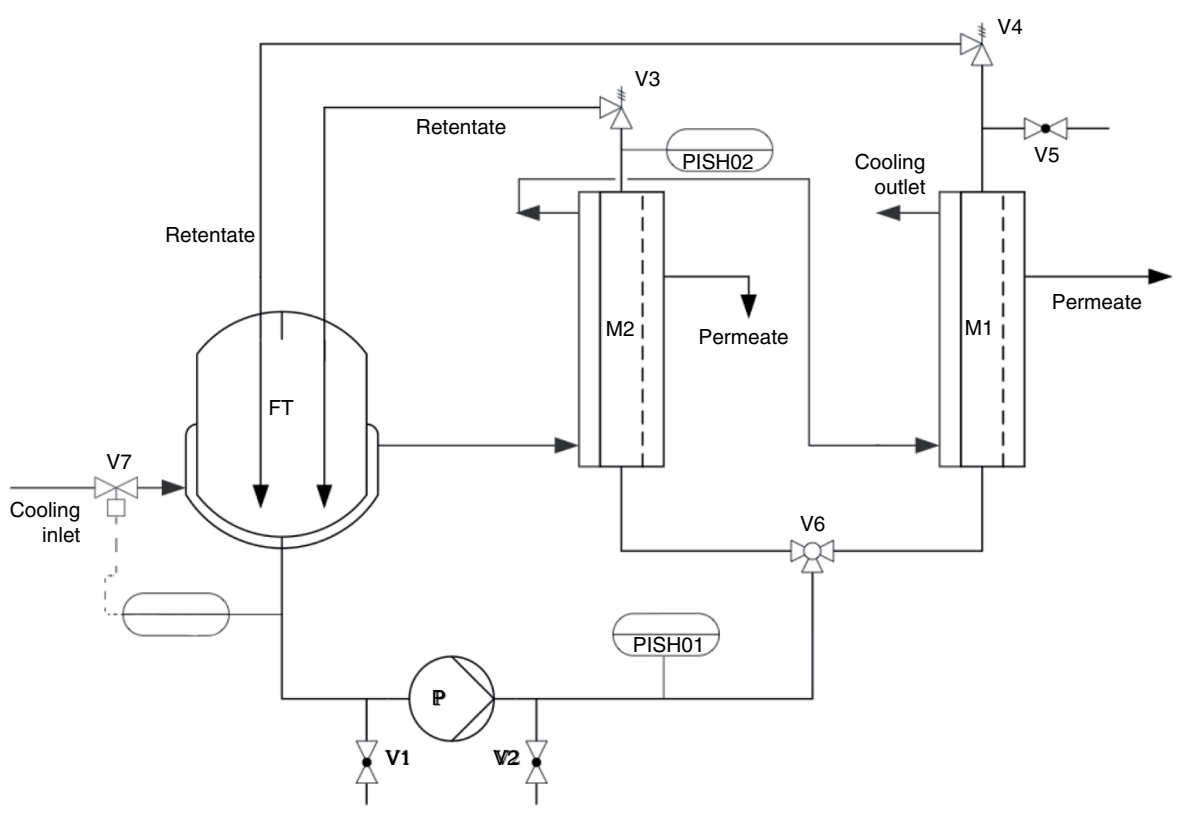

FIGURE. 1. Flow diagram of the bench-scale RO unit. V1, V2: emptying valves (pump inlet and outlet respectively); V3, V4: pressure regulating valves for module 2 and 1 respectively; V5: venting valve for module M1; V6: three-way valve to select desired working membrane module; V7: magnetic valve for cooling jacket inlet; M1: flat-sheet membrane module; M2: spiral-wounded module; P: feedstock pump; FT: feedstock tank; PISH01, PISH02: pressure gauges; TICSH01: temperature gauge.

TABLE 1. Nominal characteristics of the selected membranes.

\begin{tabular}{|c|c|c|}
\hline Parameters & Param & tric value \\
\hline Membrane type & $\mathrm{NF}$ & $\mathrm{RO}$ \\
\hline Manufacturer & GE (USA) & GE (USA) \\
\hline Model series & DK & $\mathrm{AK}$ \\
\hline $\begin{array}{l}\text { Permeability }\left(\mathbf{m}_{0}\right), \mathbf{L} / \\
\text { hm² bar }^{2}\end{array}$ & $8.2 \pm 0.3$ & $6.2 \pm 0.2$ \\
\hline Configuration & Flat-sheet & Flat-sheet \\
\hline Chemical composition & ${ }^{\mathrm{c}} \mathrm{TFC}^{\mathrm{a}} \mathrm{PA} / /^{\mathrm{b}} \mathrm{PS}$ & Asymmetric ${ }^{a} \mathrm{PA}$ \\
\hline Average pore size, $\mathrm{nm}$ & 0.5 & - \\
\hline${ }^{\mathrm{d}}$ MWCO, Da & $50-300$ & - \\
\hline Maximum pressure, bar & 32 & 8.7 \\
\hline $\begin{array}{l}\text { Maximum temperature, } \\
{ }^{\circ} \mathbf{C}\end{array}$ & 90 & 50 \\
\hline
\end{tabular}

Bench-scale NF and RO experiments were run in a semi-batch mode, conducted in tangential-flow at ambient temperature $\left(22 \pm 0.1^{\circ} \mathrm{C}\right)$ and turbulent regime over the membrane. The operating pressures were fixed at 5, 7 and 9 bars for the experimental runs with the NF (DK series) membrane, in order to work in a low-pressure energy-saving range, whereas 3, 5 and 8 (maximum operating pressure 8.7 bar) for the experiments with the RO membrane (AK series), respectively.
All the membrane experiments were run with the highest feed volume recovery possible (Y,\%), which is approximately $80-90 \%$. The operating procedure consisted of continuously recycling the concentrate stream back into the feed-water tank where it steadily collected the permeate stream, which was replaced by the same volume of fresh pretreated OMW. Periodically, samples of the permeate stream were collected in a cumulative vessel and analyzed in order to evaluate the membrane separation effectiveness with respect to the iron recovery, as well as COD and conductivity rejection. The membrane productivity was assayed by measuring the permeate flux during operation time by weighing the mass of collected permeate on a precision electronic mass balance (AX -120 Cobos, $0.1 \mathrm{mg}$ accuracy).

After each semi-batch run, the membrane was recovered for the following experiment by cleaning it in situ with $0.1-0.15 \% \mathrm{w} / \mathrm{v} \mathrm{NaOH}$ and $0.1-0.15 \%$ w/v sodium dodecyl sulfate (SDS) solutions (provided by Panreac S.A.).

The membrane performances were measured in terms of permeate flux and solute rejection. The observed iron rejection, as well as COD and conductivity, were calculated as follows:

$$
\mathrm{R}_{\mathrm{i}}(\%)=\left(1-\left(\mathrm{c}_{\mathrm{p}, \mathrm{i}} / \mathrm{c}_{\mathrm{f}, \mathrm{i}}\right)\right) \times 100
$$

where $c_{p, i}$ is the concentration of the solute $i$ in the permeate stream, and $c_{f, i}$ the concentration of the solute $i$ in the feed-water tank. 
The saturation index (SI) was also calculated following ASTM International (2001). The SI serves to gather information about the tendency of the feed and concentrate streams to lead to the formation of precipitates on the membrane surface, and is very useful to elaborate corrosion control programs to prevent from scaling on the membranes (APHA, AWWA, WPCF, 1992; ASTM International, 2001).

The SI can be determined by means of the following expression (ASTM International, 2001; Fariñas Iglesias, 1998):

$$
\mathrm{SI}=\mathrm{pH}-\mathrm{pHs}
$$

where $p H$ is that in the secondary-treated OMW stream, whereas $p H s$ is the solubility $\mathrm{pH}$ of the effluent.

For a target feed volume recovery of the feedstream fixed (Y), the concentration of a component $i$ in the concentrate stream will be (ASTM International, 2001):

$$
\left[\mathrm{X}_{\mathrm{i}}\right]_{\mathrm{r}}=\left[\mathrm{x}_{\mathrm{i}}\right]_{\mathrm{f}}-(1-(\mathrm{Y} / 100))
$$

where:

$\left[\mathrm{x}_{\mathrm{i}}\right]_{\mathrm{r}}=$ concentration $(\mathrm{mol} / \mathrm{kg})$ of the $i$ component in the concentrate stream

$\left[\mathrm{x}_{\mathrm{i}}\right]_{\mathrm{f}}=$ concentration $(\mathrm{mol} / \mathrm{kg})$ of the $i$ component in the feed-stream

$\mathrm{Y}=$ feed volume recovery factor $(\%)$

\subsection{Analytical procedures}

All the analytical methods were carried out in triplicate with analytical-grade reagents. Chemical oxygen demand (COD), total phenols (TPh), total suspended solids (TSS), electro-conductivity (EC), $\mathrm{pH}$ and particle size distribution (Plus90 nano-sizer, Brookhaven) were measured following standard methods (Greenberg et al., 2005).

For the measurement of the total iron concentration, all iron ions were reduced to iron ions (II) in a thioglycolate medium with a derivative of triazine, forming a reddish-purple complex that was determined photometrically at $565 \mathrm{~nm}$ (Standard German methods ISO 8466-1 and German DIN 38402 A51) (Greenberg et al., 2005).

\section{RESULTS AND DISCUSION}

\subsection{Physcochemical composition of OMW prior to membrane processes}

The physicochemical composition of the pretreated OMW is given in Table 2. The goal of the present study was to experimentally evaluate, on a preliminary lab-scale research, the feasibility of a further treatment of the effluent exiting the Fentonlike process by means of NF or RO technologies for
TABLE 2. Physicochemical composition of secondary-treated OMW.

\begin{tabular}{lc}
\hline Parameters & Parametric value \\
\hline $\mathbf{p H}$ & $7.8-8.2$ \\
Conductivity, mS/cm & $3.5-5.5$ \\
Total suspended solids, mg/L & $14-16$ \\
COD, mg/L & $120.5-226.6$ \\
Total phenols, $\boldsymbol{\mu g} / \mathrm{L}$ & $390-980$ \\
Total iron, $\boldsymbol{\mu g} / \mathrm{L}$ & $400-1000$ \\
\hline
\end{tabular}

both the recovery of iron to re-use it as catalyst to reduce its consumption in the Fenton-like reactor, and the removal of the COD and high EC remaining. The intention was to achieve suitability for reusing the final effluent in the olive oil production process and therefore closing the loop, and evaluate the efficiency of the pretreatment to preserve the membranes from fouling.

\subsection{Membranes permeate productivity}

In first place, the virgin NF and RO membranes' pure water permeability $\left(\mathrm{m}_{0}\right)$ was calculated (Table 1 ) by measuring the permeate flux with $\mathrm{MilliQ}^{\circledR}$ water $(18 \mathrm{M} \Omega \cdot \mathrm{cm})$ over a range of applied pressures at constant ambient temperature $\left(22 \pm 0.1^{\circ} \mathrm{C}\right)$ and turbulent cross-flow conditions (tangential velocity $5.09 \mathrm{~m} / \mathrm{s})$. In the same way, virgin membrane permeability coefficients for the pretreated OMW (m) were additionally calculated. The linear relationship between the permeate flux-net operating pressures for both pure water and pre-treated OMW were fitted. The membranes' pure water permeability coefficients $\left(\mathrm{m}_{0}\right)$, in $\mathrm{L} / \mathrm{hm}^{2}$ bar, were found to be equal to 6.1 for AK (RO membrane) and 8.2 for DK (NF membrane). Lower membranes permeability for the pre-treated OMW (m), in L/hm² bar, was confirmed: 3.9 for AK module RO membrane and 5.3 for DK module NF membrane. These flux gaps can be explained by the concentration polarization buildup in the boundary region of the membranes.

Next, semi-batch runs were performed with each membrane following the procedure described in section 2.3. Experiments were conducted at different operating pressures: 3,5 and 8 bar for the AK series RO membrane (the maximum allowable pressure for this membrane is 8.7 bar, hence a safety margin was adopted), and 5, 7 and 9 bar for the DK series NF membrane (low pressure framework, in order to obtain comparable results with respect to the RO membrane). Otherwise, turbulent cross-flow conditions (Reynolds number $>4000$ ) were set, so as to ensure a proper shear rate over the membrane and thus avoid fouling and concentration polarization phenomena as far as possible (Mott and Untener, 2014). The temperature conditions during the 
experiments were maintained at ambient temperatures $\left(22 \pm 0.1{ }^{\circ} \mathrm{C}\right)$. The influent to the membranes was the effluent from the above described physicochemical secondary treatment (refer to section 2.1), with the characteristics reported in Table 2.

The mean permeate fluxes yielded with each membrane were enhanced linearly upon increasing the operating pressure within the respective pressure range of each of the selected membranes (Figure 2). Increments of the permeate production were found to fit a linear trend upon increase of the net driving force, namely operating pressure, for both membranes tested. However, the composite polyamide/polysulfone NF membrane (DK) is able to yield greater permeate flux productions than those obtained with the RO (AK) one. At an operating pressure of 5 bar, up to $15.9 \mathrm{~L} / \mathrm{hm}^{2}$ permeate flux was yielded by the AK (RO) membrane, whereas upon the same operating pressure with the DK (NF) membrane, a permeate flux equal to $25.3 \mathrm{~L} / \mathrm{hm}^{2}$ was measured, which is $37.2 \%$ higher. Otherwise, under an operating pressure of 8 bar, about $30.9 \mathrm{~L} /$ $\mathrm{hm}^{2}$ permeate flux was obtained with the AK (RO) membrane, while a permeate flux of up to $47.4 \mathrm{~L} /$ $\mathrm{hm}^{2}$ was measured upon a similar pressure (9 bar) with the DK (NF) membrane.

The higher permeate flux obtained with the DK membrane is owed to the nano-porous structure nature of NF membranes, in which convective transport occurs, where, as in RO membranes, which are widely accepted to be homogeneous surfaces, though exhibiting imperfections related to their fabrication process, e.g. interfacial polymerization and phase inversion, the solution diffusion takes place.

The selected NF membrane is a highly productive one, capable of offering very high fluxes at low operating pressures, thereby it seemed a priori

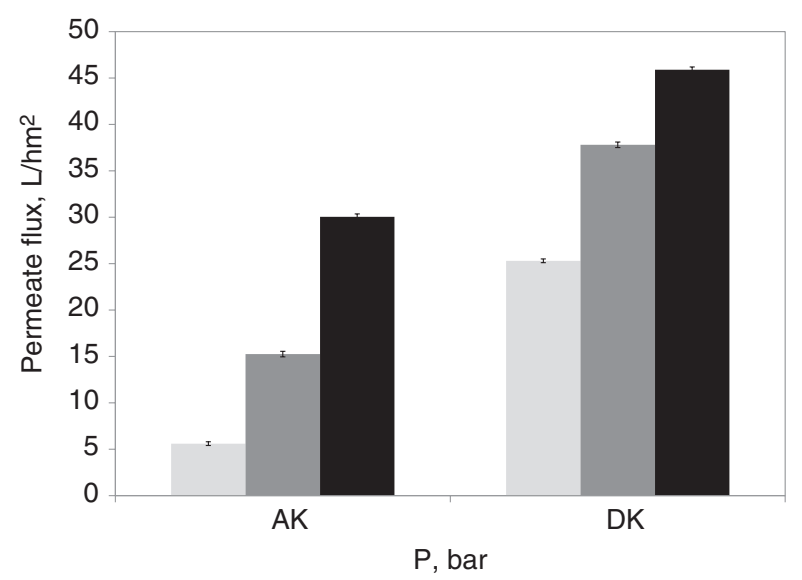

Figure. 2. Permeate flux values yielded by the selected membranes: AK series (RO) ( $\square, \square 5$ and $\square$ bar) and DK series $(\mathrm{NF})(\square 5,-7$ and $\square 9$ bar $)$. an optimum membrane from the point of view of the optimization of operating costs. The selection of the proper operating pressure is the key to all membrane processes, in terms of capital and operating expenses, commonly referred in engineering as "capex" and "opex". Operating at higher pressure leads to major permeate production, involving smaller membrane area and shortened working periods, while the other side of the balance implies more energy consumption for the same amount of influent.

Moreover, another key parameter when projecting membrane treatment plants is the feed volume recovery factor $(\mathrm{Y}, \%)$. This is very relevant and and is also connected to membrane fouling. An excessive feed volume recovery would lead to fouling issues in a shorter period of time, especially in case of batch or semi-batch systems where the bulk becomes increasingly concentrated, and more irretrievable or irreversible if scaling is a potential type of fouling in the specific system like the one in this research work (due to the presence of colloidal iron).

Inorganic fouling, in particular that generated by colloidal iron precipitates, has paramount importance as evidenced from the manufacturers' recommendations on iron concentrations in feed waters and from the problems frequently encountered in membrane facilities. Previous studies have warned that a clearly detectable decline in the permeation rate, linear in time, is attained in the iron concentration range of a few $\mathrm{ppm}$. Given that the solubility of ferric ions at $\mathrm{pH}=7$ is estimated to be $5.9 \cdot 10^{-10} \mathrm{~mol} / \mathrm{L}$, even at a total concentration of $1 \mathrm{ppb}$ almost all iron will be in precipitated form (Yiantsios and Karabelas, 2002). Membrane fouling problems have been reported even at lower concentrations for dissolved iron than those recommended by manufacturers, thus this limit should be considered tentative (Yiantsios and Karabelas, 2002).

In addition, calcium leads to the formation of scaling on the fouled membranes, mainly in the form of calcium carbonate, chlorides and sulfates. In this regard, it is important to highlight the role of certain ionic species such as calcium ions, which promote the aggregation of the organic matter by intra and intermolecular bridge formation mechanisms (Madaeni and Samieirad, 2010).

The SI calculated following ASTM International (2001) (see section 2.3) was found to be 0.4 for a $Y$ factor of $80 \%$, increasing up to 0.9 for a $Y$ equal to $90 \%$. This means that higher feed recoveries are not recommended, given that saturation of the concentrate stream driven back to the bulk tank will lead to deleterious fouling issues, caused by the promotion of scaling formation given by precipitation of carbonates as well as fouling by colloidal iron. Hence, a feed volume recovery of $\mathrm{Y}=80 \%$ should be adopted. 


\subsection{Membrane rejection performance towards iron}

In Table 3, the rejection efficiencies for both membranes with regard to the recovery of iron are reported. A rejection ranging from 95.1 - 99.1\% for an operating pressure between 5 - 9 bar was registered for the NF membrane, whereas the RO membrane yielded a rejection efficiency for iron of $100 \%$ disregarding the operating pressure.

The rejection behavior of the membrane was further studied and modelized by means of a leaky solution-diffusion model (Jain and Gupta, 2006):

$$
\mathrm{R}_{\mathrm{i}}=\mathrm{P}_{\mathrm{TM}} \cdot \sigma_{\mathrm{i}} /\left(\mathrm{P}_{\mathrm{TM}}+\beta_{\mathrm{i}}\right)
$$

where the rejection of the solute $i\left(\mathrm{R}_{\mathrm{i}}\right)$ depends primarily on the trans-membrane pressure $\left(\mathrm{P}_{\mathrm{TM}}\right)$ and two parameters, $\sigma_{i}$ which is a reflection coefficient indicating the rejection capability of the membrane $\left(0<\sigma_{\mathrm{i}}<1\right)$ and $\beta_{i}$ which is a fitting parameter. Accurate predictions of the experimental results were attained by the applied leaky solutiondiffusion model in both cases (coefficient of determination $\mathrm{R}^{2} \geq 0.99$ ).

Results from the fitting of the iron rejection values (Table 3) reveal a $\sigma_{i}$ value equal to 1 and a $\beta_{i}$ value equal to 0.5 for the NF membrane, whereas for the RO membrane these values were equal to 1 and 0.01 , respectively. These results are in very good agreement with the rejection nature of $\mathrm{NF}$ and $\mathrm{RO}$ membranes.

These results indicate that both membranes exhibit a good performance for the rejection of

TABLE 3. Iron rejection efficiencies and measured values in permeate streams.

\begin{tabular}{lccc}
\hline Membrane & Op. $\mathbf{P}$, (bar) & Iron rejection $(\%)$ & $\begin{array}{c}\text { Permeate iron } \\
(\boldsymbol{\mu g} / \mathbf{L})\end{array}$ \\
\hline DK (NF) & 5 & 95.1 & $19.6-49$ \\
& 7 & 97.5 & $10-25$ \\
& 9 & 99.1 & $3.6-9$ \\
AK (RO) & 3 & 100 & n.o. \\
& 5 & 100 & n.o. \\
& 8 & 100 & n.o. \\
\hline
\end{tabular}

the iron $(99.1 \%$ for the DK series NF membrane vs. $100 \%$ for the AK series RO membrane) in the OMW stream exiting the Fenton-like secondary treatment, thus permitting the recovery of iron in the concentrate stream in order to recycle it back into the oxidation reactor to reduce catalyst consumption. Finally, the COD values in the permeate streams were 53.4 - 74.5 vs. $1.4-1.9 \mathrm{mg} / \mathrm{L}$ for $\mathrm{NF}$ and RO, whereas the EC was measured to be 2459 - 2719 vs. $31.1-169.1 \mathrm{mg} / \mathrm{L}$ for NF and RO, permitting the re-use of the permeate stream for irrigation.

\subsection{Membranes plant dimension}

Finally, the required membrane area was calculated on the basis of a daily amount of $10 \mathrm{~m}^{3}$ of OMW treatment need and considering $10 \mathrm{~h}$ operation a day (Table 4). The number of the necessary membrane modules $\left(\mathrm{N}_{\text {modules }}, 32 \mathrm{~m}^{2}\right.$ each) was also estimated, as well as the overdesign (OD) of the membrane area. For this purpose, the estimated RO membrane area $\left(\mathrm{A}_{\mathrm{m}}\right)$ needed for the treatment of the secondary-treated OMW was calculated with the following equation, derived from the boundary flux theory previously validated by the Stoller and Ochando-Pulido (Ochando and Stoller, 2014; Stoller and Ochando, 2014, 2015):

$$
\mathrm{A}_{\mathrm{m}}=\mathrm{V}_{\mathrm{f}} \cdot(\mathrm{Y} / 100) \cdot(1+(\mathrm{OD} / 100)) / \mathrm{J}_{\mathrm{b}}
$$

where $A_{m}$ is the required membrane area $\left(\mathrm{m}^{2}\right), J_{b}$ is the boundary (steady-state) permeate flux value $\left(\mathrm{L} / \mathrm{hm}^{2}\right), Y$ is the target feed volume recovery set $(\%)$ (see section 3.1), $V_{f}$ is the volume of effluent feedstock to be treated $(\mathrm{L} / \mathrm{h})$ and $O D$ is the necessary membrane overdesign (\%).

The membrane overdesign was estimated with the following expression successfully used in previous work by the same Authors (Stoller and Ochando, 2014, 2015):

$$
\mathrm{OD}=100 \cdot\left(1-\left(\mathrm{J}_{\mathrm{b}}-\alpha \cdot \mathrm{P}_{\mathrm{TM}} \cdot \mathrm{t}_{\mathrm{w}}\right)\right) / \mathrm{J}_{\mathrm{b}}
$$

where $t_{w}$ is the membrane operating period time (h), $P_{T M}$ is the selected net driving pressure (bar) and $\alpha$ is the long-term fouling index $\left(\mathrm{L} / \mathrm{h}^{2} \mathrm{~m}^{2} \mathrm{bar}\right)$.

TABLE 4. Required membrane area and overdimension of each membrane operation.

\begin{tabular}{lccccc} 
Membrane & Fouling index $\left.\boldsymbol{\alpha}, \mathbf{(} \mathbf{L} \mathbf{h}^{2} \mathbf{m}^{\mathbf{2}} \mathbf{b a r}\right)$ & OD $(\mathbf{\%})$ & $\mathbf{A}_{\mathbf{m}}$ required, $\left(\mathbf{m}^{2}\right)$ & $\mathbf{A}_{\mathbf{m}}$ implemented, $\left(\mathbf{m}^{2}\right)$ & $\mathbf{N}_{\text {modules }}$ \\
\hline NF & 0.0072 & 0.8 & 23.8 & 32 & 2 \\
RO & 0.065 & 10.1 & 32.1 & 64 & 4 \\
\hline
\end{tabular}

$\mathrm{A}_{\mathrm{m} \text { required }}$ : required membrane area; $\mathrm{A}_{\mathrm{m} \text { implemented }}$ : implemented membrane area; OD: membrane area overdimension; $\mathrm{N}_{\text {modules: }}:$ number of membrane modules necessary. 
A thorough description of these equations and calculations can be found in Stoller and Ochando (2015).

An $A_{m}$ equal to $23.8 \mathrm{~m}^{2}$ was estimated for the $\mathrm{NF}$ membrane whereas $32.1 \mathrm{~m}^{2}$ for the RO one. Applying a conservative safety margin of $10 \%$, final $A_{m}$ of $26.3 \mathrm{~m}^{2}$ and $35.2 \mathrm{~m}^{2}$ would be necessary, respectively. This means one NF membrane module (plus another in parallel which works alternatively when the cleaning protocol is performed on the used NF membrane), where two RO modules are needed (plus 2 additional in parallel, operating alternatively during the performance of the cleaning protocol on the used RO membranes).

\section{CONCLUSIONS}

In this work, two different membranes, one nanofiltration (NF) and a low-pressure reverse osmosis (RO), are examined with a double aim: the main one is the recovery of the iron used as catalyst in the former Fenton-like secondary treatment of OMW.

The results indicate that both membranes exhibit a good performance towards the rejection of iron (99.1\% for the DK series NF membrane vs. $100 \%$ for the AK series RO membrane) in the OMW stream after the Fenton-like secondary treatment. This would permit the recovery of iron in the concentrate stream in order to recycle it back into the oxidation reactor to reduce the consumption of catalyst. Finally, the permeate streams could be re-used for irrigation.

However, the productivity of the selected NF membrane increases upon lowing operating pressures, about $30.9 \mathrm{~L} / \mathrm{hm}^{2}$ under at 8 bar with the RO membrane while $38.2-47.4 \mathrm{~L} / \mathrm{hm}^{2}$ upon $8-9$ bar with the NF membrane. Moreover, a sensibly lower fouling index was measured on the NF membrane (0.0072 in contrast with 0.065$)$, which ensures major steady-state performance on this membrane and longer service lifetime. Furthermore, this also results in a lower required membrane area, which is 4 modules in the case of RO in contrast with 2 modules for NF.

\section{ACKNOWLEDGMENTS}

The Spanish Ministry of Science and Innovation is gratefully acknowledged for having funded the projects CTQ2007-66178 and CTQ2010-21411, as well as the University of Granada.

\section{REFERENCES}

Akar T, Tosun I, Kaynak Z, Ozkara E, Yeni O, Sahin E N, Akar S T. 2009. An attractive agro-industrial by-product in environmental cleanup: Dye biosorption potential of untreated olive pomace. J. Hazard. Mater. 166, 1217-1225. http:// dx.doi.org/10.1016/j.jhazmat.2008.12.029

Akdemir EO, Ozer A. 2009. Investigation of two ultrafiltration membranes for treatment of olive oil mill wastewater.
Desalination 249, 660-666. http://dx.doi.org/10.1016/j. desal.2008.06.035

Aktas ES, Imre S, Esroy L. 2001. Characterization and lime treatment of olive mill wastewater. Water Res. 35, 2336-2340.

Al-Malah K, Azzam MOJ, Abu-Lail NI. 2000. Olive mills effluent (OME) wastewater post-treatment using activated clay. Sep. Purif. Technol. 20, 225-234. http://dx.doi.org/10.1016/ S1383-5866(00)00114-3

Annesini M, Gironi F. 1991. Olive oil mill effluent: ageing effects on evaporation behavior. Water Research, 25, 1157-1960. http://dx.doi.org/10.1016/0043-1354(91)90210-H

APHA, AWWA, WPCF. 1992. Standard Methods for water and wastewater analysis. Díaz de Santos, p. 1816, ISBN: 84-7978-031-2, Madrid.

ASTM International D 4582 - 91, 2001. Standard Practice for Calculation and Adjustment of the Stiff and Davis Stability Index for Reverse Osmosis.

Beltrán J, Torregrosa J, García J, Domínguez JR. 2000. Ozone treatment of olive mill wastewater. Grasas Aceites 51, 32-46. http://dx.doi.org/10.3989/gya.2000.v51.i5.428

Baccar R, Bouzid J, Feki M, Montiel A. 2009. Preparation of activated carbon from Tunisian olive-waste cakes and its application for adsorption of heavy metal ions. J. Hazard. Mater. 162, 1522-1529. http://dx.doi.org/10.1016/j.jhaz mat.2008.06.041

Borja R, Raposo F, Rincón B. 2006. Treatment technologies of liquid and solid wastes from two-phase olive oil mills. Grasas Aceites 57, 32-46.

Cegarra J, Paredes C, Roig A, Bernal MP, García D. 1996. Use of olive mill wastewater compost for crop production. Int. Biodet. Biodegrad. 38, 193-203. http://dx.doi.org/10.1016/ S0964-8305(96)00051-0

Coskun T, Debik E, Demir N M. 2010. Treatment of olive mill wastewaters by nanofiltration and reverse osmosis membranes. Desalination 259, 65-70. http://dx.doi.org/10.1016/j. desal.2010.04.034

Ena A, Carlozzi P, Pushparaj B, Paperi R, Carnevale S, Sacchi A. 2007. Ability of the aquatic fern Azolla to remove chemical oxygen demand and polyphenols from olive mill wastewater. Grasas Aceites 58, 32-46.

Fariñas Iglesias M. 1998. Ósmosis inversa: fundamentos, tecnología y aplicaciones. Ed. McGraw-Hill.

Garcia-Castello E, Cassano A, Criscuoli A, Conidi C, Drioli E. 2010. Recovery and concentration of polyphenols from olive mill wastewaters by integrated membrane system. Water Res. 44, 3883-3892. http://dx.doi.org/10.1016/j.watres. 2010.05 .005

Garrido Hoyos SE, Martínez Nieto L, Camacho Rubio F, Ramos Cormenzana A. 2002. Kinetics of aerobic treatment of olive-mill wastewater (OMW) with Aspergillus terreus. Process Biochem. 37, 1169-1176. http://dx.doi. org/10.1016/S0032-9592(01)00332-6

Grafias P, Xekoukoulotakis NP, Mantzavinos D, Diamadopoulos E. 2010. Pilot treatment of olive pomace leachate by vertical-flow constructed wetland and electrochemical oxidation: an efficient hybrid process. Water Research 44, 2773-2780. http://dx.doi.org/10.1016/j.watres.2010. 02.015

Greenberg AE, Clesceri LS, Eaton AD. 2005. Standard Methods for the Examination of Water and Wastewater, APHA/ AWWA/WEF, 22th ed., Washington DC. Cabs.

Haddadin M S Y, Haddadin J, Arabiyat O I, Hattar B. 2009. Biological conversion of olive pomace into compost by using Trichoderma harzianum and Phanerochaete chrysosporium. Biores. Tech. 100, 4773-4782. http://dx.doi. org/10.1016/j.biortech.2009.04.047

Hodaifa G, Ochando-Pulido JM, Rodriguez-Vives S, MartínezFérez A. 2013a. Optimization of continuous reactor at pilot scale for olive-oil mill wastewater treatment by Fenton-like process. Chem. Eng. J. 220, 117-124. http:// dx.doi.org/10.1016/j.cej.2013.01.065

Hodaifa G, Eugenia-Sánchez M, Sánchez S. 2008. Use of industrial wastewater from olive-oil extraction for biomass production of Scenedesmus obliquus. Bioresour. Technol.99,1111-1117.http://dx.doi.org/10.1016/j.biortech. 2007.02 .020 
Hodaifa G, Ochando-Pulido JM, Ben-Driss-Alami S, RodriguezVives S, Martínez-Férez A. 2013b. Kinetic and thermodynamic parameters of iron adsorption onto olive stones. Ind. Crops Prod. 49, 526-534. http://dx.doi.org/10.1016/j. indcrop.2013.05.039

Inan H, Dimoglo A, Șimșek H, Karpuzcu M. 2004. Olive oil mill wastewater treatment by means of electro-coagulation. Sep. Purif. Technol. 36, 23-31. http://dx.doi.org/10.1016/ S1383-5866(03)00148-5

Jain S, Gupta SK, 2004. Analysis of modified surface force pore flow model with concentration polarization and comparison with Spiegler-Kedem model in reverse osmosis systems. J. Membr. Sci. 232, 45-62. http://dx.doi.org/10.1016/j. memsci.2003.11.021

Lafi WK, Shannak B, Al-Shannag M, Al-Anber Z, Al-Hasan M. 2009. Treatment of olive mill wastewater by combined advanced oxidation and biodegradation. Separ. Purif. Technol. 70, 141-146. http://dx.doi.org/10.1016/j. seppur.2009.09.008

Madaeni SS, Samieirad S. 2010. Chemical cleaning of reverse osmosis membrane fouled by wastewater. Desalination $\mathbf{2 5 7}$, 80-86. http://dx.doi.org/10.1016/j.desal.2010.03.002

Martínez Nieto L, Ben Driss Alami S, Hodaifa G, Faur C, Rodríguez Vives S, Giménez Casares JA, Ochando J. 2010. Adsorption of iron on crude olive stones. Ind. Crop. Prod. 32, 467-471. http://dx.doi.org/10.1016/j. indcrop.2010.06.017

Martínez Nieto L, Hodaifa G, Rodríguez Vives S, Giménez Casares JA, Ochando J. 2011a. Flocculation-sedimentation combined with chemical oxidation process. Clean Soil, air, water 39, 949-955. http://dx.doi.org/10.1002/ clen.201000594

Martínez Nieto L, Hodaifa G, Rodríguez Vives S, Giménez Casares JA, Ochando J. 2011b. Degradation of organic matter in olive oil mill wastewater through homogeneous Fenton-like reaction. Chem. Eng. J. 173, 503-510. http:// dx.doi.org/10.1016/j.cej.2011.08.022

Marques IP. 2001. Anaerobic digestion treatment of olive mill wastewater for effluent re-use in irrigation. Desalination 137 , 233-239. http://dx.doi.org/10.1016/S0011-9164(01)00224-7

Mott R L, Untener J A, Applied Fluid Mechanics, 7th edition, University of Dayton, 2014

Ochando-Pulido JM, Rodriguez-Vives S, Martínez-Férez A. 2012a. The effect of permeate recirculation on the depuration of pretreated olive mill wastewater through reverse osmosis membranes. Desalination 286, 145-154. http:// dx.doi.org/10.1016/j.desal.2011.10.041

Ochando-Pulido JM, Hodaifa G, Rodriguez-Vives S, MartínezFérez A. 2012b. Impacts of operating conditions on reverse osmosis performance of pretreated olive mill wastewater. Water Res. 46, 4621-4632. http://dx.doi.org/10.1016/j. watres.2012.06.026

Ochando-Pulido JM, Hodaifa G, Victor-Ortega MD, RodriguezVives S, Martínez-Férez A, 2013a. Effective treatment of olive mill effluents from two-phase and three-phase extraction processes by batch membranes in series operation upon threshold conditions. J. Hazard. Mater. 263, 168-176. http://dx.doi.org/10.1016/j.jhazmat.2013.03.041

Ochando-Pulido JM, Hodaifa G, Victor-Ortega MD, RodriguezVives S, Martínez-Férez A, 2013b. Reuse of olive mill effluents from two-phase extraction process by integrated advanced oxidation and reverse osmosis treatment, $J$. Hazard. Mater. 263, 158-67. http://dx.doi.org/10.1016/j. jhazmat.2013.07.015

Ochando-Pulido JM, Hodaifa G, Victor-Ortega MD, MartínezFérez A, 2014. A novel photocatalyst with ferromagnetic core used for the treatment of olive oil mill effluents from two-phase production process. The Scientific World Journal 2014. http://dx.doi.org/10.1155/2013/196470

Ochando-Pulido J.M., Stoller M, 2014. Boundary flux optimization of a nanofiltration membrane module used for the treatment of olive mill wastewater from a two-phase extraction process. Separ. Purif. Technol. 130, 124-131. http://dx.doi.org/10.1016/j.seppur.2014.04.035

Papadimitriou EK, Chatjipavlidis I, Balis C. 1997. Application of composting to olive mill wastewater treatment. Environ.
Technol. 18, 101-107. http://dx.doi.org/10.1080/0959333 1808616517

Paraskeva P, Diamadopoulos E. 2006. Technologies for olive mill wastewater (OMW) treatment: A review. J. Chem. Technol. Biotechnol. 81, 475-485. http://dx.doi.org/10.1002/ jctb. 1553

Paraskeva C A, Papadakis V G, Tsarouchi E, Kanellopoulou D G, Koutsoukos P G. 2007. Membrane processing for olive mill wastewater fractionation. Desalination 213, 218-229. http://dx.doi.org/10.1016/j.desal.2006.04.087

Russo C. 2007. A new membrane process for the selective fractionation and total recovery of polyphenols, water and organic substances from vegetation waters (VW). J. Membr. Sci. 288, 239-246. http://dx.doi.org/10.1016/j. memsci.2006.11.020

Sacco O, Stoller M, Vaiano V, Ciambelli P, Chianese A, Sannino D. 2012. Photocatalytic degradation of organic dyes under visible light on $\mathrm{n}$-doped photocatalysts. Int. J. Photoenergy 2012. http://dx.doi.org/10.1155/2012/626759

Sarika R, Kalogerakis N, Mantzavinos D. 2005. Treatment of olive mill effluents. Part II. Complete removal of solids by direct flocculation with poly-electrolytes. Environ. Int. 31, 297-304. http://dx.doi.org/10.1016/j.envint.2004.10.006

Stasinakis A S, Elia I, Petalas A V, Halvadakis C P. 2008. Removal of total phenols from olive-mill wastewater using an agricultural by-product, olive pomace. J. Hazard. Mater. 160, 408-413. http://dx.doi.org/10.1016/j.jhazmat.2008.03.012

Stoller M. 2008. Technical optimization of a dual ultrafiltration and nanofiltration pilot plant in batch operation by means of the critical flux theory: a case study. Chem. Eng. Process. 47, 1165-1170. http://dx.doi.org/10.1016/j.cep.2007.07.012

Stoller M. 2009. On the effect of flocculation as pretreatment process and particle size distribution for membrane fouling reduction. Desalination 240, 209-217. http://dx.doi. org/10.1016/j.desal.2007.12.042

Stoller M. 2011. Effective fouling inhibition by critical flux based optimization methods on a NF membrane module for olive mill wastewater treatment. Chem. Eng. J. 168, 1140-1148. http://dx.doi.org/10.1016/j.cej.2011.01.098

Stoller M, Ochando-Pulido JM. 2012. Going from a critical flux concept to a threshold flux concept on membrane processes treating olive mill wastewater streams. Procedia Eng. 44, 607-608. http://dx.doi.org/10.1016/j.proeng.2012.08.500

Stoller M, Ochando-Pulido J.M., 2014. About merging threshold and critical flux concepts into a single one: the boundary flux. The Scientific World J. 2014, 656101. http:// dx.doi.org/10.1155/2014/656101

Stoller M, Ochando-Pulido J.M., 2015. The boundary flux handbook: A comprehensive database of critical and threshold flux values for membrane practitioners, Amsterdam (Netherlands), Elsevier.

Stoller M, Ochando-Pulido JM, di Palma L, Martínez-Férez A. 2015. Membrane process enhancement of 2-phase and 3 -phase olive mill wastewater treatment plants by photocatalysis with magnetic-core titanium dioxide nanoparticles. J. Ind. \& Eng. Chem. In press, 2015. http://dx.doi. org/10.1016/j.jiec. 2015.05.015

Tekin A R, Coşkun Dalgıç A. 2000. Biogas production from olive pomace. Resour. Conserv. Recy. 30, 301-313. http://dx.doi. org/10.1016/S0921-3449(00)00067-7

Tezcan Ü, Uğur S, Koparal AS, Öğütveren ÜB. 2006. Electrocoagulation of olive mill wastewaters. Sep. Purif. Technol. 52, 136-141. http://dx.doi.org/10.1016/j.seppur.2006. 03.029

Turano E, Curcio S, De Paola M G, Calabrò V, Iorio G. 2002. An integrated centrifugation-ultrafiltration system in the treatment of olive mill wastewater. J. Membr. Sci. 206, 519-531. http://dx.doi.org/10.1016/S0376-7388(02)00369-1

Vincent-Vela MC, Cuartas-Uribe B, Álvarez-Blanco S, LoraGarcía J. 2011. Analysis of fouling resistances under dynamic membrane filtration. Chem. Eng. Process. 50, 404 408. http://dx.doi.org/10.1016/j.cep.2011.02.010

Yiantsios S G, Karabelas A J. 2002. An assessment of the Silt Density Index based on RO membrane colloidal fouling experiments with iron oxide particles. Desalination 15, 229238. http://dx.doi.org/10.1016/S0011-9164(02)01015-9 